\title{
Retardo da realização da IATF sobre o desempenho reprodutivo na estação de acasalamento de vacas de corte lactantes
}

\author{
[Delay of beginning to FTAI on reproductive performance during to mating \\ season of beef lactating cows] \\ C. Gottschall ${ }^{1,2}$, H.R. Bittencourt ${ }^{3}$, R.C. Mattos $^{4}$, R.M. Gregory ${ }^{4}$ \\ ${ }^{1}$ Faculdade de Medicina Veterinária - ULBRA - Canoas, RS \\ ${ }^{2}$ Aluno de pós-graduação - UFRGS - Porto Alegre, RS \\ ${ }^{3}$ PUCRS - Porto Alegre, RS \\ ${ }^{4}$ Faculdade de Medicina Veterinária - UFRGS - Porto Alegre, RS
}

\begin{abstract}
RESUMO
Compararam-se efeitos de diferentes protocolos para a IATF com o acasalamento natural (Controle) sobre o desempenho reprodutivo de 249 vacas Aberdeen Angus, distribuídas em cinco grupos: Controle $(\mathrm{n}=50)$; Crestar $2^{\circ}$ uso ( $\left.n=64\right)$; OvSynch ( $\left.n=65\right)$; Primer $1^{\circ}$ uso $(n=35)$ e Primer $2^{\circ}$ uso $(n=35)$. A IATF dos animais dos grupos Crestar $2^{\circ}$ uso, OvSynch, e Primer $1^{\circ}$ uso foi realizada 27 dias após o início da estação do grupo controle e a IATF do grupo Primer $2^{\circ}$ uso ocorreu 38 dias após o início da estação do grupocontrole. A partir de sete dias após a IATF, os animais foram submetidos ao repasse por touros até o término da estação de acasalamento, que foi de 91 dias para o grupo-controle, 64 dias para os grupos Crestar $2^{\circ}$ uso, OvSynch e Primer $1^{\circ}$ uso e de 53 dias para o grupo Primer $2^{\circ}$ uso. A taxa de gestação ao final da estação de acasalamento não se diferenciou entre os grupos ( $P>0,05)$, sendo de $85,9 \%$; 83,1\%; $82,9 \% ; 88,6 \%$ e $80,0 \%$, respectivamente, para Crestar $2^{\circ}$ uso; OvSynch; Primer $1^{\circ}$ uso; Primer $2^{\circ}$ uso e Controle. A taxa de parição resultante da IATF foi de $23,4 \% ; 29,2 \%$; 48,6\% e $62,9 \%$ para os grupos Crestar $2^{\circ}$ uso, OvSynch, Primer $1^{\circ}$ uso, Primer $2^{\circ}$ uso, respectivamente, com diferença significativa $(\mathrm{P}<0,05)$ entre Crestar e Primer $1^{\circ}$ e $2^{\circ}$ uso. OvSynch não se diferenciou de Crestar e Primer $1^{\circ}$ uso. Primer $1^{\circ}$ uso não se diferenciou de Primer $2^{\circ}$ uso. A perda gestacional, do diagnóstico de gestação ao nascimento, foi de 10,5\%. O intervalo de partos estimado (IEP) não apresentou diferenças, com média de 478 dias. O escore de condição corporal (ECC) de fêmeas gestantes ao final da estação reprodutiva foi diferente do de fêmeas não gestantes (controle), mas não dos demais grupos, possivelmente pela influência do tratamento em induzir a ciclicidade dos animais com ECC inferior. $\mathrm{O}$ atraso da realização da IATF após 27 ou 38 dias do início da estação de acasalamento não afetou a taxa de gestação final e o IEP dos animais, quando comparado ao acasalamento por touros.
\end{abstract}

Palavras-chave: vacas de corte, perdas reprodutivas, escore de condição corporal, bovinos, condição ovariana

\begin{abstract}
The effects of different FTAI protocols were compared to the natural mating of bulls on the reproductive performance of 249 Aberdeen Angus cows. Five groups were formed: Control (n=50); Crestar $2^{\text {nd }}$ use $(n=64)$; OvSynch (n=65); Primer $1^{\text {st }}$ use $(n=35)$ and Primer $2^{\text {nd }}$ use $(n=35)$. The FTAI of the animals in the Crestar $2^{\text {nd }}$ use, OvSynch and Primer $1^{\text {st }}$ use groups was accomplished 27 days after the beginning of the mating season for the control group and the FTAI in the Primer $2^{\text {nd }}$ use group happened 38 days after the beginning of the mating season of the control group. From seven days after the FTAI cows were exposed to bulls until the end of the mating season. The mating season was of 91 days for the control group, 64 days for the Crestar $2^{\text {nd }}$ use, OvSynch and Primer $1^{\text {st }}$ use groups and 53 days for the Primer $2^{\text {nd }}$ use group. The pregnancy rate at the end of the mating season didn't differ among the groups $(P>0.05)$,
\end{abstract}

Recebido em 25 de julho de 2011

Aceito em 2 de janeiro de 2012

E-mail: carlosgott@cpovo.net 
being 85.9; 83.1; 82.9; 88.6 and 80.0\% respectively, for Crestar $2^{\text {nd }}$ use, OvSynch, Primer $1^{\text {st }}$ use, Primer $2^{\text {nd }}$ use and Control. The birth rate resulting from FTAI was 23.4; 29.2; 48.6 and 62.9\% for the Crestar $2^{\text {nd }}$ use, OvSynch, Primer $1^{\text {st }}$ use, Primer $2^{\text {nd }}$ use groups, with significant difference $(P<0.05)$ among Crestar and Primer $1^{\text {st }}$ and $2^{\text {nd }}$ use. OvSynch didn't differ in Crestar and Primer $1^{\text {st }}$ use. Primer $1^{\text {st }}$ use didn't differ from Primer $2^{\text {nd }}$ use. The average reproductive losses between the gestation diagnosis and the birth were $10.5 \%$. The estimated calving interval (CI) didn't present differences among the animal groups, with an average of 478 days. The body condition score (BCS) of pregnant cows at the end of the reproductive station differed from BCS of empty cows in the control group, but it didn't differ in the other groups, possibly due to the hormonal treatment influence in inducing the oestrus and ovulation in animals with lower BCS. The delay of the accomplishment of FTAI after 27 or 38 days of the beginning of the mating season didn't affect the final pregnancy rate and CI of the cows, when compared to natural mating.

Keywords: beef cows, reproductive losses, body condition score, bovine, ovarian condition

\section{INTRODUÇÃO}

A indução de estros e a sincronização da ovulação para o uso da inseminação artificial em tempo fixo (IATF) são alternativas descritas para a busca de aumento de produtividade em sistemas de produção de bovinos de corte (Baruselli et al., 2004; Madureira e Pimentel, 2005). Segundo Baruselli et al. (2002), Meneghetti e Vasconcelos (2008) e Meneghetti et al. (2009), o uso da IATF em rebanhos de vacas de cria possibilita que as vacas sejam inseminadas e se tornem gestantes no início da estação de monta, diminuindo com isto o período de serviço e aumentando a eficiência reprodutiva do rebanho. Outras vantagens da utilização da IATF resumem-se à possibilidade de uso de sêmen de touros com superioridade genética comprovada (Pegorer et al., 2011); à concentração de animais em estro em um curto espaço de tempo; à redução do período de parição; à padronização do nascimento de bezerros; ao aumento do peso à desmama e ao aumento da probabilidade de reconcepção na estação subsequente (Gregory, 2002; Gottschall et al., 2008a; Sá Filho et al., 2009).

Baruselli et al. $(2002,2004)$ e Penteado et al. (2005) demonstraram que tratamentos com progesterona e progestágenos foram eficientes em induzir a ciclicidade ao início da estação de monta de vacas de corte lactantes. Os autores verificaram uma antecipação na gestação resultante da IATF, quando esta foi comparada a métodos mais tradicionais (touros ou inseminação convencional).

Em sistemas de produção de gado de corte, a adequação de práticas de manejo à condição específica da propriedade é um requisito fundamental para o sucesso da atividade (Radostits, 2001). Em situações específicas, como, por exemplo, sobreposição de tarefas, uso de mangueiras para outras práticas, indisponibilidade temporária de mão-de-obra, grande número de lotes de animais, inseminação de diversas categorias e necessidade de reaproveitamento de dispositivos intravaginais, poderá ocorrer retardo na utilização da IATF, sem coincidir com o início da estação de acasalamento.

A hipótese levantada neste trabalho é a de que o retardo na utilização da IATF durante a estação de acasalamento não compromete o desempenho reprodutivo de vacas de corte lactantes, quando comparadas ao acasalamento por touros.

O objetivo deste estudo foi avaliar o impacto do retardo da IATF após o uso de diferentes protocolos de sincronização de estros e comparar o desempenho reprodutivo entre os protocolos e o acasalamento apenas com touros durante a estação reprodutiva de vacas de corte com cria ao pé.

\section{MATERIAL E MÉTODOS}

O experimento foi realizado no período de novembro de 2007 a dezembro de 2008, em propriedade particular, no município de Alegrete-RS (Fazenda Paraíso). A propriedade, conforme a classificação de Köppen, localiza-se em região denominada "variedade Cfa", caracterizada por presença de chuvas regularmente distribuídas, com média anual de $1.350 \mathrm{~mm}$. Possui temperatura média anual próxima a $18,6^{\circ} \mathrm{C}$ variando entre $13,1^{\circ} \mathrm{C}$ em 
julho e $24^{\circ} \mathrm{C}$ em janeiro. $\mathrm{O}$ grupo de animais foi manejado extensivamente em campo natural, bioma em que predominam comunidades vegetais compostas, em sua grande maioria, por espécies de gramíneas de valor forrageiro, leguminosas e também plantas herbáceas com cerca de 400 espécies de gramíneas e 150 de leguminosas (Boldrini, 1997). Os animais receberam suplementação mineral ad libitum, proveniente de um produto comercial com 63 gramas de fósforo por quilograma.

Foram utilizadas 249 vacas lactantes adultas, com idade média de 5,7 anos, da raça Aberdeen
Angus, identificadas individualmente por meio de brincos plásticos e tatuagem correspondente. Os animais foram separados em cinco grupos, para a avaliação do desempenho reprodutivo durante a estação de acasalamento. Os quatro primeiros grupos foram submetidos a diferentes protocolos de IATF e, após, ao repasse com touros. O grupo controle foi submetido apenas ao acasalamento com touros. Por ocasião do início da estação de acasalamento (Tab. 1), os animais

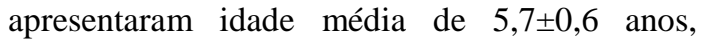
escore de condição corporal entre 2,0 e 3,5, com

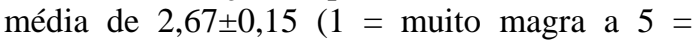
muito gorda), segundo Lowman et al. (1976).

Tabela 1. Formação dos grupos experimentais com vacas lactantes Aberdeen Angus

\begin{tabular}{|c|c|c|c|c|c|c|}
\hline Grupo & $\begin{array}{l}\text { Número de } \\
\text { animais }\end{array}$ & $\%$ & $\begin{array}{l}\text { Idade } \\
\text { (anos) }\end{array}$ & ECC & $\begin{array}{c}\text { Data média } \\
\text { do parto }\end{array}$ & $\begin{array}{c}\text { Estação } \\
\text { acasalamento }\end{array}$ \\
\hline Crestar $2^{\circ}$ uso & 64 & 25,7 & 5,7 & 2,68 & $11 / 9$ & $17 / 12-19 / 02$ \\
\hline OvSynch & 65 & 26,1 & 5,8 & 2,70 & $10 / 9$ & $17 / 12-19 / 02$ \\
\hline Primer $1^{\circ}$ uso & 35 & 14,1 & 5,6 & 2,60 & $14 / 9$ & $17 / 12-19 / 02$ \\
\hline Primer $2^{\circ}$ uso & 35 & 14,1 & 5,7 & 2,68 & $10 / 9$ & $28 / 12-19 / 02$ \\
\hline Controle (touro) & 50 & 20,1 & 5,5 & 2,67 & $20 / 9$ & 20/11-19/02 \\
\hline Total & 249 & 100,0 & $5,7 \pm 0,6$ & $2,67 \pm 0,15$ & $13 / 09 \pm 13$ & $===$ \\
\hline
\end{tabular}

Os animais foram submetidos ao manejo tradicional da propriedade. A estação de acasalamento iniciou em 20/11 e terminou em 19/02 do ano seguinte para o grupo-controle. Ao início da estação de acasalamento, os animais do grupo-controle tinham, em média, 58 dias pósparto. Os grupos Crestar $2^{\circ}$ uso, OvSynch e Primer $1^{\circ}$ uso foram submetidos à IATF em 17/12, apresentando, em média, 94 dias pósparto, enquanto o grupo Primer $2^{\circ}$ uso (implante reutilizado do grupo Primer $1^{\circ}$ uso) foi submetido à IATF em 28/12, apresentando nesta ocasião, em média, 107 dias pós-parto.

O grupo Crestar $2^{\circ}$ uso era composto por 64 vacas com cria ao pé, submetidas ao protocolo de Crestar ${ }^{\circledR}$ de $2^{\circ}$ uso. No dia zero, foi colocado o implante auricular (previamente usado por oito dias), seguido pela aplicação de $1 / 2$ dose de valerato de estradiol (VE) intramuscular (equivalente a 2,5mg de VE e 1,5mg de norgestomet). No oitavo dia, foi retirado o implante, seguido pela aplicação intramuscular de PGF2a $(375 \mu \mathrm{g}$ de cloprostenol sódico Sincrocio ${ }^{\circledR}$, Ourofino; $1,5 \mathrm{~mL}$ ). No nono dia, $24 \mathrm{~h}$ após a retirada do implante, foi aplicado $1 \mathrm{mg}$ de benzoato de estradiol (B.E) (Sincrodiol®,
Ourofino; $1 \mathrm{~mL})$. A IATF foi realizada no $10^{\circ}$ dia, $52 \mathrm{~h}$ após a retirada do implante.

O grupo OvSynch era composto por 65 vacas com cria ao pé, submetidas ao protocolo OvSynch (Pursley et al., 1995). No dia zero, pela manhã, foi realizada a aplicação intramuscular de um análogo do $\mathrm{GnRH}$, na dose de $10 \mu \mathrm{g}$ de buserelina (Sincroforte, Ourofino; 2,5mL). Sete dias após, os animais receberam 500ug de cloprostenol sódico (Sincrocio®), Ourofino; $2 \mathrm{~mL}$ ) intramuscular. No nono dia pela manhã, os animais receberam nova aplicação intramuscular de $10 \mu \mathrm{g}$ de buserelina (Sincroforte, Ourofino; $2,5 \mathrm{~mL}$ ). A IATF foi realizada à tarde, $10 \mathrm{~h}$ após a aplicação da buserelina;

Os grupos Primer $1^{\circ}$ e $2^{\circ}$ uso eram compostos por 35 vacas com cria ao pé, cada. Os animais receberam no dia zero, dia aleatório do ciclo estral, a inserção de dispositivo Primer® intravaginal novo $\left(1^{\circ}\right.$ uso) com $1 \mathrm{~g}$ de progesterona ( $\mathrm{P} 4)$ e usado $\left(2^{\circ}\right.$ uso). Por ocasião da inserção do dispositivo, os animais receberam a injeção intramuscular de $2 \mathrm{mg}$ de benzoato de estradiol (B.E) (Sincrodiol®, Ouro fino, $2 \mathrm{~mL}$ ). No oitavo dia (D8), os dispositivos foram removidos, e os animais receberam $375 \mu \mathrm{g}$ de 
cloprostenol sódico (Sincrocio®, Ouro fino, $1,5 \mathrm{~mL}$ ) intramuscular. No nono dia pela manhã, foi aplicado $1 \mathrm{mg}$ de B.E. intramuscular. Na tarde do décimo dia, 52 horas após a remoção do dispositivo, ou 30 horas após a aplicação de B.E, todos os animais foram inseminados.

O grupo controle, composto por 50 vacas com cria ao pé, foi submetido apenas ao acasalamento com touros, durante 90 dias, na proporção de $4 \%$ de touros submetidos previamente à avaliação andrológica. Os animais dos grupos submetidos à IATF tiveram os bezerros separados temporariamente, 56 horas antes da IATF, retornando para as mães após a realização desta. No grupo-controle, os bezerros também foram separados temporariamente por 56 horas. O sêmen utilizado foi de um touro da raça Nelore. A inseminação foi realizada por um único técnico, com experiência comprovada. Sete dias após a realização da IATF, foram soltos os touros Aberdeen Angus, com fertilidade comprovada por avaliação andrológica, na proporção de $2,5 \%$ do número total de vacas. Sessenta dias após o término da estação de acasalamento (19/02), foi realizado o diagnóstico para avaliar a taxa de gestação final. Os partos na estação subsequente foram controlados, e a data de nascimento e a raça dos bezerros anotada. Desta forma, pôde ser estimada a parição resultante da IATF.

A partir das informações coletadas, foi possível calcular: taxa de gestação ao final da estação de acasalamento, taxa de parição resultante da IATF, data média de parto na estação subsequente, perdas entre o diagnóstico de gestação e o parto, idade média dos terneiros ao desmame. $\mathrm{O}$ intervalo entre partos (IEP) estimado foi obtido pela diferença em dias da data da segunda parição (2008) menos a data da primeira parição (2007). O IEP para as vacas diagnosticadas vazias por ocasião do diagnóstico de gestação, após o término da estação reprodutiva, foi fixado em 730 dias. Esse valor de 730 dias corresponde a uma estimativa para fins de cálculo, pois os animais não gestantes (vazios) foram engordados e descartados da propriedade; o escore de condição ovariana (ECO) foi obtido por palpação retal, por técnico capacitado, por ocasião da inserção dos dispositivos de progesterona. Nesse momento, também foi realizada a avaliação do grupo- controle. Foi usado o escore sugerido por Madureira e Pimentel (2005), modificado, sendo atribuído o escore 1 para fêmeas que possuem ovários pequenos, duros e lisos; 2 para fêmeas que possuem ovários com comprimento entre 1530mm, ausência de CL e turgidez no útero, incluindo fêmeas cujos folículos atingem a fase de dominância $(\geq 8,5 \mathrm{~mm})$; e 3 para fêmeas ciclando, ovários com comprimento acima de $30 \mathrm{~mm}$, macios, presença de CL, ou útero com turgidez acentuada, denotando a presença de folículos grandes (>10mm).

Os dados foram submetidos à análise de variância e à diferença entre médias pelo teste Tukey ou pelo teste $t$ de Student. Dados de gestação e perdas reprodutivas foram comparados por qui-quadrado. Regressão logística foi utilizada para avaliar a gestação em função da idade, ECC, dias pós-parto, ECO e tratamento. Os dados foram analisados por meio do software SPSS 13.0. Interações possíveis entre as variáveis foram testadas.

\section{RESULTADOS E DISCUSSÃO}

A taxa de gestação ao final da estação de acasalamento foi de $83,9 \%$, sem diferença entre os tratamentos.

Baruselli et al. (2004), em experimento similar, mas com a coincidência da IATF ao início da estação de acasalamento, encontraram taxa de gestação final, após 90 dias de estação, de $80,9 \% ; 79,0 \% ; 88,3$; e $85,0 \%$, respectivamente, para os grupos controle (touro), CIDR, Crestar e OvSynch $(\mathrm{P}>0,05)$, resultados semelhantes ao presente trabalho, que teve o retardo da IATF em relação aos touros. Penteado et al. (2005) relataram taxa de gestação final, respectivamente, de $92,7 \%$ e $83,2 \% \quad(\mathrm{P}<0,05)$ para o grupo de vacas com cria ao pé submetidas à IATF, seguida pelo repasse com touros e para o grupo acasalado apenas com touros durante 90 dias de estação de acasalamento. Segundo os autores, a diferença de $9,5 \%$ a favor do grupo IATF mais touros pode ser uma consequência dos tratamentos com progestágenos, que possibilitaram emprenhar cerca de $50 \%$ do rebanho por ocasião da IATF ao início da estação de monta, além de induzir a ciclicidade no período pós-parto em vacas de corte lactantes. 
Tabela 2. Taxa de gestação ao final da estação de acasalamento, taxa de parição da inseminação artificial em tempo fixo e perdas reprodutivas do diagnóstico de gestação ao parto em vacas de corte lactantes submetidas aos diferentes tratamentos

\begin{tabular}{|c|c|c|c|c|}
\hline \multirow[t]{2}{*}{ Grupo } & \multirow[t]{2}{*}{$\mathrm{N}$} & Gestação final & Parição da IATF & \multirow{2}{*}{$\begin{array}{c}\text { Perdas do diagnóstico de } \\
\text { gestação ao parto } \\
\text { n } \%\end{array}$} \\
\hline & & $\mathrm{n} \%$ & $\mathrm{n} \%$ & \\
\hline Crestar $2^{\circ}$ uso & 64 & $55 / 6485,9$ & $15 / 6423,4^{a}$ & $5 / 559,1 \mathrm{ab}$ \\
\hline OvSynch & 65 & $54 / 6583,1$ & $19 / 6529,2 \mathrm{ab}$ & $10 / 5418,5 b$ \\
\hline Primer $1^{\circ}$ uso & 35 & $29 / 3582,9$ & $17 / 3548,6 b c$ & $3 / 298,6 \mathrm{ab}$ \\
\hline Primer $2^{\circ}$ uso & 35 & $31 / 3588,6$ & $22 / 3562,9 c$ & $1 / 313,2 \mathrm{a}$ \\
\hline Controle (touro) & 50 & $40 / 5080,0$ & $===$ & $3 / 407,5 \mathrm{ab}$ \\
\hline Total & 249 & $209 / 24983,9$ & $73 / 17940,8$ & $22 / 20910,5$ \\
\hline
\end{tabular}

Médias seguidas por letras diferentes na mesma coluna diferem entre si $(\mathrm{P}<0,05)$ pelo teste qui-quadrado.

No trabalho de Penteado et al. (2005), o intervalo entre o início da estação de acasalamento e a concepção foi 22 dias menor para os grupos que receberam a IATF. No presente trabalho, a IATF dos grupos Crestar, OvSynch e Primer $1^{\circ}$ uso foi realizada 27 dias após o início da estação de acasalamento para o grupo-controle. A IATF do grupo Primer $2^{\circ}$ uso ocorreu 38 dias após o início da estação de acasalamento para o grupocontrole. Mesmo assim, a taxa de gestação final não apresentou diferença entre os grupos.

A taxa de parição média, resultante da IATF, foi de 40,8\%, com diferença entre grupos (Tab. 2). $\mathrm{O}$ tratamento à base de Primer $2^{\circ}$ uso mostrou-se superior $(62,9 \%)$, sem diferir do Primer $1^{\circ}$ uso $(48,6 \%)$, enquanto o tratamento Crestar $2^{\circ}$ uso com $1 / 2$ dose de valerato mostrou o pior resultado $(23,4 \%)$, sem diferir do tratamento OvSynch $(29,2 \%)$, e este não diferiu do Primer $1^{\circ}$ uso.

Moreira (2002) relatou taxas de nascimento resultante da IATF em 179 vacas com cria ao pé submetidas ao protocolo Crestar de $28,4 \%$, valor muito próximo ao encontrado neste trabalho. No presente experimento, o Crestar era de $2^{\circ}$ uso, e foi aplicada $1 / 2$ dose de valetaro de estradiol na colocação do implante. No entanto, Almeida $e t$ al. (2006) não encontraram diferenças em gestação entre implantes novos e reutilizados, com taxas de gestação à IATF, respectivamente, de $49,1 \%$ e $50,0 \%(P>0,05)$, para vacas Nelore com cria ao pé. Colazo et al. (2005) e Sá Filho et al. (2006) relataram o uso de doses menores de valerato de estradiol por ocasião da inserção do implante auricular Crestar. Segundo os resultados, a redução para $2 / 5$ da dose ou $1 / 2$ dose de valerato não acarreta em prejuízos para os programas de sincronização de estros seguido por IATF. Nestes casos, deverá ser aplicada
PGF2alfa por ocasião da retirada do implante e benzoato no dia seguinte como indutor de ovulação, como ocorreu no presente experimento.

O protocolo OvSynch é um método bastante difundido nos Estados Unidos, entretanto os resultados de concepção apresentam grande variação. Geary et al. $(1998,2001)$ reportaram taxas de concepção entre $53 \%$ e $66 \%$ para vacas de corte lactantes, sendo estas superiores a animais submetidos ao aleitamento temporário e em animais cíclicos. Os autores citados acima afirmaram que o tratamento é capaz de induzir a ciclicidade em número significativo de animais em anestro. Algumas pesquisas geradas em regiões tropicais questionam a efetividade do tratamento em animais acíclicos. Cavalieri (2004), em estudo na Austrália, comparando resultados de OvSynch com a sincronização de estros pelo uso de PGF2 $\alpha$, demonstrou a incapacidade do protocolo OvSynch em produzir aumentos significativos no desempenho reprodutivo de nove rebanhos de bovinos de corte. No Brasil, Alvarez et al. (2003) relataram taxas de concepção entre $21,7 \%$ e $44,4 \%$ em vacas lactantes.

Baruselli et al. (2004) relataram taxa de gestação à IATF de 15,0\%; 42,7\% e 52,0\%, respectivamente, para os grupos OvSynch, Crestar e CIDR, com superioridade significativa $(\mathrm{P}<0,05)$ para os protocolos com emprego de progesterona (CIDR e Crestar), atribuindo a diferença ao elevado percentual de anestro do rebanho experimental, que, segundo os autores, interfere negativamente na resposta ao protocolo OvSynch. Entretanto, Geary et al. (1998) relataram maior taxa de gestação $(\mathrm{P}<0,025)$ para o protocolo OvSynch em relação ao protocolo 
Syncro-Mate-B (implante auricular à base de norgestomet - semelhante ao Crestar), descrevendo a capacidade do OvSynch em induzir a ovulação fértil em animais cíclicos e em anestro. Neste trabalho, diferentemente das citações de Geary (1998) e Baruselli et al. (2004), o OvSynch não se diferenciou dos protocolos à base de progesterona (Crestar $2^{\circ}$ uso e Primer $1^{\circ}$ uso).

As perdas reprodutivas do diagnóstico de gestação até o parto variaram entre 3,2\% e 18,5\% entre os grupos, com média de 10,5\%. Neste caso, a diferença foi calculada entre os bezerros nascidos vivos e o diagnóstico de gestação. Pela metodologia aplicada, não foi possível estimar se as perdas referem-se à inseminação ou ao repasse por touros. O grupo OvSynch apresentou o maior percentual de perdas $(18,5 \%)$, sem se diferenciar do Crestar $2^{\circ}$ uso, Primer $1^{\circ}$ uso e Controle. O grupo Primer $2^{\circ}$ uso apresentou $\mathrm{o}$ menor percentual de perdas reprodutivas $(3,2 \%)$, sem se diferenciar do Crestar $2^{\circ}$ uso, Primer $1^{\circ}$ uso e Controle. No presente trabalho, pelo reduzido número de animais (em um grupo apenas uma perda), a sensibilidade do teste pode ter sido comprometida. Todavia, as perdas mensuradas são significativas e refletem a média descrita na literatura.

Gottschall et al. (2008b) relataram perdas reprodutivas entre $7,6 \%$ e $19,3 \%(\mathrm{P}<0,01)$ para vacas multíparas e primíparas, respectivamente. Gottschall et al. (2009) mensuraram perdas reprodutivas entre o $40^{\circ}$ e o $49^{\circ}$ dia até o $117^{\circ}$ e o $126^{\circ}$ dia gestacional entre $3,8 \%$ e $9,3 \%$, com média de 6,5\%, sem diferença entre os tratamentos de vacas submetidas à IATF póssincronização com CIDR. Forar et al. (1995) relataram perdas gestacionais entre $5,2 \%$ e $10,6 \%$, para rebanhos de bovinos de corte. Em extensa revisão, Sartori (2004) citou inúmeros fatores que contribuem para as perdas reprodutivas, ressaltou especialmente a mortalidade embrionária precoce, não mensurada no presente trabalho. Holm et al. (2008) detectaram perdas reprodutivas em novilhas, do diagnóstico de gestação até o parto, de 12,6\% e $12,3 \%$ para dois grupos de animais submetidos à inseminação artificial com observação de estro e indução com prostaglandina, respectivamente. Dahlen et al. (2003) relataram perdas reprodutivas de $11,7 \%$ em novilhas de corte entre o primeiro diagnóstico de gestação por ultrassonografia aos 30-35 dias pós-IA e o segundo diagnóstico por palpação retal 120-125 dias após IA. No trabalho de Dahlen et al. (2003), entre o segundo diagnóstico de gestação e o parto, as perdas reprodutivas foram de 12,3\%. Poucos trabalhos descrevem as diferenças entre a taxa de gestação obtida após a IA/TF e a taxa real de nascimentos. Esses valores são significativos e não devem ser desprezados em uma análise técnica e econômica. No presente experimento, deixaram de nascer 22 bezerros de inseminação, em 209 animais (10,5\%). Stevenson et al. (2003) relataram valores similares em gado de corte, em que deixaram de nascer 24 bezerros de inseminação, em 223 animais $(10,8 \%)$.

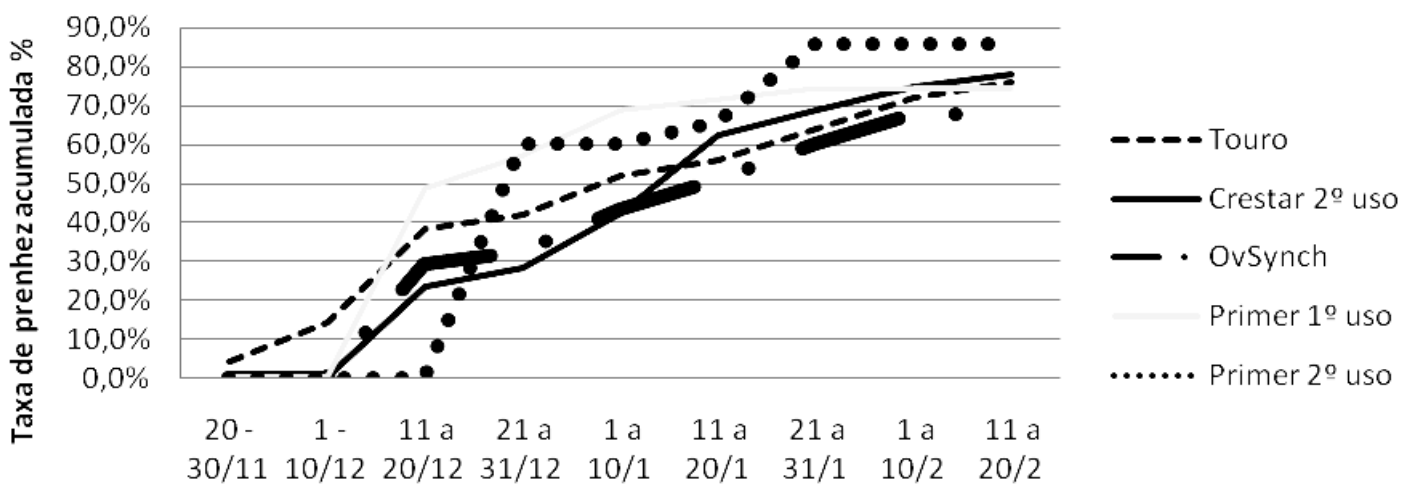

Estação de acasalamento

Figura 1. Taxa de gestação acumulada de vacas de corte durante a estação de acasalamento, submetidas a diferentes protocolos reprodutivos. 
No momento da realização da $1^{\mathrm{a}}$ IATF, $38 \%$ das vacas do grupo-controle estavam gestantes, frente a $31 \%$ das fêmeas submetidas à IATF, nesse período. Por ocasião da $2^{\mathrm{a}}$ IATF (Primer $2^{\circ}$ uso), $60 \%$ das vacas emprenharam, enquanto a taxa de gestação acumulada para as vacas do grupo controle foi de $42 \%$, e $36 \%$ para as vacas submetidas a $1^{\text {a }}$ IATF (Fig. 1). Por meio do emprego da IATF, mesmo após o início da estação de monta, foi possível emprenhar um número significativo de animais, além de possivelmente o tratamento hormonal induzir a ciclicidade (Baruselli et al., 2004; Penteado et al., 2005) no período pós-parto, em vacas de corte lactantes. Nesse estudo, o retardo da realização da IATF na respectiva estação de acasalamento, em 27 e 38 dias, não afetou o resultado reprodutivo ao final dela.

Tabela 3. Data de parto na estação subsequente e intervalo entre partos (IEP) em dias, segundo os tratamentos (grupo)

\begin{tabular}{|c|c|c|c|c|}
\hline Grupo & $\mathrm{N}$ & $\begin{array}{c}\text { Data de parto na estação } \\
\text { subsequente }\end{array}$ & $\mathrm{N}$ & IEP \\
\hline Crestar & 50 & $20 / 10 \pm 18,1 b c$ & 64 & $475,8 \pm 136,7$ \\
\hline OvSynch & 44 & $17 / 10 \pm 18,2 \mathrm{ab}$ & 65 & $507,9 \pm 155,6$ \\
\hline Primer $1^{\circ}$ uso & 26 & $5 / 10 \pm 11,2 \mathrm{a}$ & 35 & $473,6 \pm 153,5$ \\
\hline Primer $2^{\circ}$ uso & 30 & $18 / 10 \pm 13,5 b c$ & 35 & $449,1 \pm 117,4$ \\
\hline Controle (touro) & 37 & $12 / 10 \pm 24,0 \mathrm{ab}$ & 50 & $469,6 \pm 149,6$ \\
\hline Total & 187 & $16 / 10 \pm 18,5$ & 249 & $478,9 \pm 144,6$ \\
\hline
\end{tabular}

Médias seguidas por letras diferentes na mesma coluna diferem entre si $(\mathrm{P}<0,05)$ pelo teste Tukey.

O tratamento do grupo Primer $1^{\circ}$ uso resultou em antecipação na data de parto da estação subsequente, sem se diferenciar dos gruposcontrole e OvSynch. Estes dois últimos não se diferenciaram dos grupos Primer $2^{\circ}$ uso e Crestar. É importante ressaltar que a IATF dos grupos Crestar, OvSynch e Primer $1^{\circ}$ uso foi realizada 27 dias após o início da estação de acasalamento em relação ao grupo controle. A
IATF do grupo Primer $2^{\circ}$ uso ocorreu 38 dias após o início da estação de acasalamento para o grupo-controle.

O IEP estimado dos animais não diferiu entre os grupos. Nesse cálculo, foram analisadas informações de animais que emprenharam e pariram no ano subsequente e de animais que não pariram.

Tabela 4. Idade em anos, escore de condição ovariana (ECO), escore de condição corporal (ECC) e data de parto no ano anterior de vacas prenhes e vazias ao final da temporada reprodutiva

\begin{tabular}{lccc} 
Variável & $\begin{array}{c}\text { Prenhes } \\
\mathrm{n}=209\end{array}$ & $\begin{array}{c}\text { Vazias } \\
\mathrm{n}=40\end{array}$ & Valor de $\mathrm{p}$ \\
\hline Idade & $5,7 \pm 0,60$ & $5,6 \pm 0,64$ & 0,17 \\
ECO & $2,5 \pm 0,50 \mathrm{a}$ & $2,3 \pm 0,32 \mathrm{~b}$ & $0,04^{*}$ \\
ECC & $2,7 \pm 0,16 \mathrm{~A}$ & $2,6 \pm 0,12 \mathrm{~B}$ & $0,001^{* *}$ \\
Data parto anterior & $14 / 09 \pm 13$ & $12 / 09 \pm 14$ & 0,59 \\
\hline
\end{tabular}

Médias seguidas por letras minúsculas diferentes na mesma linha $(\mathrm{P}<0,05)$ e por letras maiúsculas diferentes na mesma linha $(\mathrm{P}<0,01)$ diferem entre si pelo teste $t$ de Student.

Não houve efeito significativo da idade (Tab. 4) sobre a taxa de gestação. O escore ovariano e o ECC das fêmeas prenhes e vazias ao final da estação de acasalamento foram significativamente diferentes. Wettemann et al. (2003) afirmaram que as reservas corporais ao parto exercem uma importante influência sobre o intervalo parto primeiro estro e ovulação em vacas de corte lactantes. Segundo os autores, a diminuição dos pulsos de $\mathrm{GnRH}$ causa redução na secreção pulsátil de LH, aumentando o período anovulatório em vacas de corte, pois a inadequada secreção de LH não permite desenvolvimento e secreção suficiente de estrógeno pelo folículo dominante para induzir o pico ovulatório de LH e o estro. 
Tabela 5. Escore de condição corporal (ECC) ao início do tratamento para a inseminação artificial em tempo fixo (IATF) em vacas prenhes e vazias ao final da temporada reprodutiva

\begin{tabular}{lccc} 
& & & \\
Tratamento & Prenhe & Vazia & Valor de $\mathrm{p}$ \\
\hline Crestar & $2,70 \pm 0,19$ & $2,61 \pm 0,09$ & 0,21 \\
OvSynch & $2,71 \pm 0,14$ & $2,64 \pm 0,11$ & 0,09 \\
Primer $^{\circ}$ uso & $2,63 \pm 0,19$ & $2,48 \pm 0,17$ & 0,09 \\
Primer 2o $^{\circ}$ uso & $2,69 \pm 0,15$ & $2,65 \pm 0,10$ & 0,64 \\
Controle (touro) & $2,69 \pm 0,12 \mathrm{a}$ & $2,60 \pm 0,09 \mathrm{~b}$ & 0,04 \\
\hline
\end{tabular}

Médias seguidas por letras diferentes na mesma linha, diferem entre si $(\mathrm{P}<0,05)$ pelo teste $t$ de Student.

Segundo Ciccioli et al. (2003), vacas que mantêm ou perdem condição corporal durante a lactação apresentam maior intervalo parto-cio e menor fertilidade. Muito embora a análise por tratamento, não tenha demontrado diferença significativa entre o ECC de vacas prenhes e vazias que foram submetidas aos tratamentos hormonais para a IATF (Tab. 5), apenas em vacas submetidas ao grupo-controle (touro) a diferença foi significativa. Esse resultado, possivelmente, seja consequência da capacidade que os tratamentos à base de hormônios tiveram em induzir a ciclicidade em alguns animais com menor condição corporal.

Gottschall et al. (2009) não encontraram diferença entre o ECC de animais prenhes e vazios ao final da estação de acasalamento, submetidos à IATF, respectivamente, de 2,7 $\pm 0,3$ e $2,7 \pm 0,4(\mathrm{P}=0,379)$. De forma similar, Lamb et al. (2001) relataram ausência do efeito do ECC em amplitude reduzida de avaliação (4,5 a 5,5 na escala de 1 a 9) sobre as taxas de concepção de animais submetidos à IATF. Os resultados do presente trabalho são similares aos relatados acima, e parte da ausência de diferença pode ser explicada pelo menor número de animais em cada tratamento (entre 35 e 65 animais).
Também é importante destacar que, na seleção de animais experimentais, os autores buscaram selecionar animais com maior homogeneidade possível e com reduzida variação no ECC. Sá Filho et al. (2009), ao avaliarem dados retrospectivos de mais de 64.000 IATF, encontraram relação positiva entre a taxa de gestação à IATF e o ECC com resultados de $43,0 \%$ para ECC $\leq 2,5 ; 49,6 \%$ para ECC 3,0 ; e $52,7 \%$ para $\mathrm{ECC} \geq 3,5$. Os autores afirmaram que o ECC é um preditor confiável de probabilidade de gestação quando utilizados protocolos com progesterona para a IATF. Esses resultados sugerem que a eficiência de protocolos que utilizam progesterona e estrógeno é dependente do ECC, sendo recomendada a utilização desses protocolos em vacas com ECC $>2,5$.

Madureira e Pimentel (2005) recomendaram a classificação de escore ovariano, avaliado por palpação retal, no momento da colocação do implante/dispositivo e a aplicação de eCG nas vacas com escore equivalente a 1 e 2 . Geary et al. (1998) relataram maiores taxas de gestação para fêmeas cíclicas submetidas à IATF após tratamento com OvSynch e Syncro-Mate-B (semelhante ao Crestar).

Tabela 6. Escore de condição ovariana (ECO) ao início do tratamento para a IATF em vacas prenhes e vazias à IATF

\begin{tabular}{lccc} 
& & & \\
Tratamento & Prenhe & Vazia & Valor de $\mathrm{p}$ \\
\hline Crestar & $2,80 \pm 0,41 \mathrm{a}$ & $2,37 \pm 0,49 \mathrm{~b}$ & 0,005 \\
OvSynch & $2,47 \pm 0,51$ & $2,44 \pm 0,50$ & 0,84 \\
Primer $1^{\circ}$ uso & $2,41 \pm 0,51$ & $2,60 \pm 0,51$ & 0,30 \\
Primer $2^{\circ}$ uso & $2,46 \pm 0,51$ & $2,50 \pm 0,52$ & 0,81 \\
\hline
\end{tabular}

Médias seguidas por letras diferentes na mesma linha diferem entre si $(\mathrm{P}<0,05)$, pelo teste $t$ de Student. 
No presente trabalho, os achados também concordaram com as afirmações de Silcox et al. (1995), Vasconcelos et al. (1997) e Geary et al. (1998). A análise isolada entre os tratamentos (Tab. 6) mostrou que o protocolo Crestar apresentou diferença altamente significativa entre o ECO de animais prenhes e não prenhes. Resultados similares são descritos por Gottschall (informação pessoal), que descreve taxa de gestação à IATF em novilhas submetidas ao tratamento Crestar de 38,4\% e 66,7\% ( $\mathrm{P}<0,05)$, respectivamente para animais com ETR 2 e 3. Entretanto, para o protocolo OvSynch, os autores descreveram taxa de gestação à IATF em novilhas de $50,0 \%$ e $59,1 \% \quad(\mathrm{P}>0,05)$, respectivamente, para animais com ETR 2 e 3. Ou seja, parece que o tratamento com o Crestar não teve capacidade de induzir adequadamente a ciclicidade ou induzir a ovulação em animais com menor ECO, enquanto os outros tratamentos não apresentaram essa diferença.

\section{CONCLUSÕES}

O retardo na utilização da IATF em aproximadamente 30 dias após o início da estação de acasalamento, seguida pelo repasse de touros, possibilita a obtenção de taxas de gestação ao final da estação, similares às taxas obtidas em estação de acasalamento tradicional com touro por 90 dias em rebanhos de vacas de corte lactantes. Perdas reprodutivas entre o diagnóstico de gestação e o nascimento são significativas. Entre os diversos protocolos utilizados, o tratamento à base de dispositivo intravaginal de progesterona, estrógeno, prostaglandina e estrógeno (PEPE) apresentou os resultados mais consistentes.

\section{REFERÊNCIAS}

ALMEIDA, A.B.; BERTAN, C.M.; ROSSA, L.A.F. et al. Avaliação da reutilização de implantes auriculares contendo norgestomet associados ao valerato ou ao benzoato de estradiol em vacas nelore inseminadas em tempo fixo. Braz. J. Vet. Res. Anim. Sci., v.43, p.456465, 2006.

ALVAREZ, R.H.; MARTINEZ, A.C.; CARVALHO, J.B.P. et al. Eficácia do tratamento Ovsynch associado à inseminação artificial prefixada em rebanhos Bos taurus e Bos indicus. Pesq. Agropec. Bras., v.38, p.317-323, 2003.
BARUSELLI, P.S.; MARQUES, M.O.; CARVALHO, N.A.T. et al. Efeito de diferentes protocolos de inseminação artificial em tempo fixo na eficiência reprodutiva de vacas de corte lactantes. Rev. Bras. Reprod. Anim., v.26, p.218-221, 2002.

BARUSELLI, P.S.; REIS, E.L.; MARQUES, M.O. et al. The use of hormonal treatments to improve reproductive performance of anestrous beef cattle in tropical climates. Anim. Reprod. Sci., v.82, p.479-486, 2004.

BOLDRINI, I.I. Campos do Rio Grande do Sul: Caracterização fisionômica e problemática ocupacional. Bol. Inst. Bioc. UFRGS, n. 56, 1997. 39p.

CAVALIERI, J. Induction of ovulation in Bos indicus and Bos taurus cattle following synchronization of oestrous cycles with emphasis on Australian studies. In: SIMPÓSIO INTERNACIONAL DE REPRODUÇÃO ANIMAL APLICADA, 1., 2004, Londrina. Anais... São Paulo: Faculdade de Medicina Veterinária e Zootecnia, Universidade de São Paulo, 2004. p.82-104.

CICCIOLI, N.H.; WETTEMANN, R.P.; SPICER, L.J. et al. Influence of body condition at calving and postpartum nutrition on endocrine function and reproductive performance of primiparous beef cows. $J$. Anim. Sci., v.81, p.3107-3120, 2003.

COLAZO, M.G.; MARTÍNEZ, M.F.; SMALL, J.A. et al. Effects of estradiol valerate on ovarian follicle dynamics and superovulatory response in progestintreated cattle. Theriogenology, v.63, p.1454-1468, 2005.

DAHLEN, C.R.; LAMB, G.C.; ZEHNDER, C.M. et al. Fixed-time insemination in peripuberal, lightweight replacement beef heifers after estrus synchronization with PGF2alpha and GnRH. Theriogenology, v.59, p.1827-1837, 2003.

FORAR, A.L.; GAY, J.M.; HANCOCK, D.D. The frequency of endemic fetal loss in dairy cattle: a review. Theriogenology, v.43, p.989-1000, 1995.

GEARY, T.W.; WHITTIER, J.C.; DOWNING, E.R. Pregnancy rates of postpartum beef cows that were synchronized using Syncro-Mate-B or the Ovsynch protocol. J. Anim. Sci., v.76, p.1523-1527, 1998.

GEARY, T.W.; SALVERSON, R.R.; WHITTIER, J.C. Synchronization of ovulation using GnRH or hCG with the CO-Synch protocol in suckled beef cows. J. Anim Sci., v.79, p.2536-2541, 2001.

GOTTSCHALL, C.S.; MARQUES, P.R.; CANELLAS, L.C. et al. Aspectos relacionados à sincronização do estro e ovulação em bovinos de corte. Hora Vet., n.164, p.43-48, 2008a. 
GOTTSCHALL, C.S.; FERREIRA, E.T.; CANELLAS, L.C. et al. Perdas reprodutivas e reconcepção em bovinos de corte segundo a idade ao acasalamento. Arq. Bras. Med. Vet. Zootec., v.60, p.414-418, 2008b.

GOTTSCHALL, C.S.; BITTENCOURT, H.; MATTOS, R. et al. Antecipação da aplicação de prostaglandina, em programa de inseminação artificial em tempo fixo em vacas de corte. Rev. Bras. Saúde Prod. Anim., v.10, p.970-979, 2009.

GREGORY, R.M. Métodos de sincronização de estros em bovinos. In: BORGES, J.B.S.; GREGORY, R.M. SIMPÓSIO DE REPRODUÇÃO BOVINA Sincronização de Estros em Bovinos, 1., Porto Alegre. Anais... Porto Alegre, RS, 2002. p.18-24.

HOLM, D.E.; THOMPSON, P.N.; IRONS, P.C. The economic effects of an estrus synchronization protocol using prostaglandin in beef heifers. Theriogenology, v.70, p.1507-1515, 2008.

LAMB, G.C.; STEVENSON, J.S.; KESLER, D.J. et al. Inclusion of an intravaginal progesterone insert plus GnRH and prostaglandin F2alpha for ovulation control in postpartum suckled beef cows. J. Anim. Sci., v.79, p.2253-2259, 2001.

LOWMAN, B.G.; SCOTT, N.; SOMERVILLE, S. Condition scoring beef cattle. Edinburgh: Scotland College of Agriculture, 1976. 8p.

MADUREIRA, E.H.; PIMENTEL, J.R.V. IATF como ferramenta para melhorar a eficiência reprodutiva. In: CONGRESSO BRASILEIRO DE REPRODUÇÃO ANIMAL, 16., 2005. Goiânia. Anais..., Goiânia, GO. p.1-8, 2005.

MENEGHETTI, M.; VASCONCELOS, J.L.M. Mês de parição, condição corporal e resposta ao protocolo de inseminação artificial em tempo fixo em vacas de corte primíparas. Arq. Bras. Med. Vet. Zootec., v.60, p.786-793, 2008 .

MENEGHETTI, M.; SÁ FILHO, O.G.; PERES, R.F.G. et al. Fixed-time artificial insemination with estradiol and progesterone for Bos indicus cows I: Basis for development of protocols. Theriogenology, v.72, p.179-189, 2009.

MOREIRA, R.J.C. Uso do protocolo Crestar® em tratamentos utilizando Benzoato de Estradiol, PGF2 $\alpha$, PMSG e GnRH para controle do ciclo estral e ovulação em vacas de corte. 2002. 48p. Dissertação (Mestrado) - Escola Superior de agricultura "Luiz de Queiroz”, Universidade de São Paulo, Piracicaba, SP.

PEGORER, M.F.; ERENO, R.L.; SATRAPA, R.A. et al. Neither plasma progesterone concentrations nor exogenous eCG affects rates of ovulation or pregnancy in fixed-time artificial insemination (FTAI) protocols for puberal Nellore heifers. Theriogenology, v.75, p.17-23, 2011.
PENTEADO, L.; SÁ FILHO, M.F.; REIS, E.L. et al. Eficiência reprodutiva em vacas Nelore (Bos indicus) lactantes submetidas a diferentes manejos durante a estação de monta. In: REUNIÃO DO COLÉGIO BRASILEIRO DE REPRODUÇÃO ANIMAL, 2005. Goiânia. Anais..., Goiânia, GO. 2005.

PURSLEY, J.R.; MEE, M.O.; WILTBANK, M.C. Synchronization of ovulation in dairy cows using PGF2a, and GnRH. Theriogenology, v.44, p.915923,1995.

RADOSTITS, O.M. Herd Health: Food Animal Production Medicine. 3.ed. Philadelphia: W. B. Saunders, 2001.

SÁ FILHO, M.F.; REIS, E.L.; AYRES, H. et al. Effect of oestradiol valerate or benzoate on induction of a new follicular wave emergence in Bos indicus cows and heifers treated with norgestomet auricular implant. Reprod. Fertil. Develop., v.18, p.289, 2006.

SÁ FILHO, O.G.; MENEGHETTI, M.; PERES, R.F.G. et al. Fixed-time artificial insemination with estradiol and progesterone for Bos indicus cows II: Strategies and factors affecting fertility. Theriogenology, v.72, p.210-218, 2009.

SARTORI, R. Fertilização e morte embrionária em bovinos. Acta Sci. Vet., v.32, supl., p.35-50, 2004.

SILCOX, R.W.; POWELL, K.L.; PURSLEY, J.R. et al. Use of GnRH to synchronize ovulation in Holstein cows and heifers treated with GnRH and prostaglandin. Theriogenology, v.43, p.325, 1995. Abstract.

STEVENSON, J.S.; JOHNSON, S.K.; MEDINABRITOS, M.A. et al. Resynchronization of estrus in cattle of unknown pregnancy status using estrogen, progesterone, or both. J. Anim. Sci., v.81, p.16811692, 2003.

VASCONCELOS, J.L.M.; SILCOX, R.W.; ROSA, G.J. et al. Synchronization rate, size of the ovulatory follicle, and conception rate after synchronization of ovulation with GnRH on different days of the estrous cycle. J. Dairy Sci., v.80, Supl. 1, p.178, 1997. Abstract.

VASCONCELOS, J.L.M.; MENEGHETTI, M.; SANTOS, R.M. Inseminação artificial em tempo fixo (IATF) em bovinos. Acta Sci. Vet., v.34, Supl. 1, p.916, 2006.

WETTEMANN, R.P.; LENTS, C.A.; CICCIOLI, N.H. et al. Nutritional and suckling-mediated anovulation in beef cows. J. Anim. Sci., v.81, p.48-59, 2003. 